\title{
Cultural Health Moments: A Search Analysis During Times of Heightened Awareness to Identify Potential Interception Points with Digital Health Consumers
}

\author{
Gulhan Bizel $^{1}$, Cecil Parmar ${ }^{1}$, Kusum Singh ${ }^{1}$, Supriya Teegala ${ }^{1} \&$ Vijay Kumar Reddy Voddi ${ }^{1}$ \\ ${ }^{1}$ Data Science Institute, Saint Peter's University, USA \\ Correspondence: Gulhan Bizel, Assistant Professor, Frank J. Guarini School of Business, Data Science Institute, \\ Saint Peter’s University, Jersey City, 07306, United States of America. E-mail: gbizel@saintpeters.edu(GB); \\ cparmar15@saintpeters.edu(C.P.); kna@saintpeters.edu(K); steegala@saintpeters.edu(S.T.); vvoddi@saintpeters. \\ edu(VV)
}

Received: November 21, 2021; Accepted: December 3, 2021; Published: December 4, 2021

\begin{abstract}
Year after year whenever someone who is considered "high profile" discovers that they have some sort of sickness or if they pass away due to a sickness, there seems to be a heightened interest in that person. At the same time however, there is a heightened awareness of the type of sickness that the person had. Finding the moments in which there is a heightened sense of awareness towards a specific topic can be something of high value to various agencies and organizations. The objective of this study was to explore the moments in which people start to do some initial search queries when there is a high-profile health moment. Once it is understood when this moment occurs, further research can be done to understand where the search behavior shifts to searches of awareness, signs, symptoms, and introspection over time.
\end{abstract}

Keywords: health, search analysis, google trends, heightened awareness, digital search, health searches

\section{Introduction}

Celebrities are known as trend setters, stars, and those whose lives inspire the rest of us "regular" people. Whenever a celebrity does something of relevance it becomes headlines whether it be good or bad; and the attention received could also be positive or negative. Chadwick Boseman was an actor who captivated fans by starring in the 2016 movie Captain America: Civil War as the hero Black Panther. He went on to reprise his role in three more feature films. Just as any other celebrity, his star was shining brighter than ever, and he was only receiving positive feedback. However, this positive feedback changed in April of 2020 when he was broadcasting a video on his Instagram live and appeared to have lost a lot of weight. Speculations occurred and many people blamed him for being a drug user. When Chadwick passed away later the same year, it was announced that he was diagnosed with Colon Cancer prior to shooting his film Black Panther in 2017 (Ugwu \& Levenson, 2020). When Chadwick Boseman passed away, searches for his name skyrocketed on Google search engine and he also became one of the highest trending topics on twitter whereas prior to his death, searches for him were non-existent. Unsurprisingly, searches for colon cancer also rose after it was announced that it was the reason for his death.

Many illnesses were initially considered such as Colon Cancer, Alzheimer's, Diabetes, and Influenza. However, it was decided that this research would be completed on Chronic Traumatic Encephalopathy (CTE), Pancreatic Cancer, and Lung Cancer. In this research, six different celebrities were investigated who passed away due to these three different sicknesses. Once it was decided who this study would be conducted on, the next step was to explore the moments in which people start to do some initial search queries during the high-profile health moment. After it was understood when this moment occurs, further research was done to understand where the search behavior shifts to searches of awareness, signs, symptoms, and introspection over time.

The first illness that was looked at was Chronic Traumatic Encephalopathy (CTE) and its effect on National Football League superstar Aaron Hernandez as well as Dr. Bennet Omalu, the discoverer of the disease. "Aaron Hernandez suffered the most severe case of chronic traumatic encephalopathy ever discovered in a person his age" (Kilgore, 2017).

The next illness was pancreatic cancer and the people who died from this sickness were Steve Jobs, the founder of Apple, and Alex Trebek, the former host of Jeopardy. Steve Jobs revealed that he has a rare form of pancreatic 
cancer in 2004 and suffered until his death in 2011. Lastly lung cancer was looked at and the people who died from this sickness were Dana Reeve, a former actress and nonsmoker, and Rush Limbaugh, an American Radio Personality. Rush Limbaugh who denied the risks of smoking for many years even saying that it would take "50 years to kill people, if it does" (Ketteler, 2021).

The structure of this research is as follows: section 2 presents an overview of the datasets used in the analysis. Section 3 presents the methodology of the data visualization by using Tableau analysis. Section 4 describes the results and discussion of the Tableau visualizations as well as an analysis on the total annual deaths caused by the specific illnesses. Lastly, Section 5 presents the conclusion.

\section{Method}

\subsection{Method Design}

Once the time span was decided where there was a heightened sense of awareness, it was realized that to understand the impact of the celebrity's death, data must be collected for at least three months prior as well as three months after their death.

During the exploratory data analysis phase of this research, data was first cleaned using Google Sheets. Columns were given more detailed names and the data type was changed for a few of the columns. Using Google Sheets, some initial graphs were created to visualize the data.

Although Google Sheets helped to understand the direction for this research, it was decided that to create better visualizations to draw insights, Tableau would be the better option. Tableau is one of the best data visualization tools today and it was used to find the correlation between the searches for diseases, keywords, and famous personalities' deaths.

In addition to Google Trends data, the death rates for the specific illnesses, and demographic data was also taken into consideration while conducting research on the various illnesses and keywords related to famous personalities.

\subsection{Datasets}

The primary source for the three datasets collected on CTE, Pancreatic Cancer, and Lung Cancer were retrieved using Google Trends. The secondary source for the data on the death rates of these illnesses were retrieved from the website www.data.world According to new research ("DATA POINTS: CANCER DEATHS," 2006).

The following three sections describe the data that was analyzed on the three specific illnesses: CTE, pancreatic cancer, and lung cancer datasets.

\subsubsection{CTE Datasets}

The first search that was conducted on Google Trends was for the keyword "CTE” from January 2004 - September 2021. After the data was collected and visualized, three major peaks were seen during the months of December 2015, September 2017, and January 2020. Upon further research it was discovered that the peak in 2015 was caused due to the movie "Concussion" being released that month. The peak in 2017 was caused due to the revelation that NFL Superstar Aaron Hernandez has the most severe case of CTE for a person of his age. With "CTE" in mind, it was decided that Google Trends data would be collected on the following key words: "Dementia" and "Concussion" due to their relationships with the illness.

Aaron Hernandez played professional football for the New England Patriots. Therefore, it was decided that data would be collected from the state of Massachusetts using the keywords "Aaron Hernandez," "Dementia," and "Concussion" from June 2017 to January 2018 in the state of Massachusetts via Google Trends.

Similarly, Dr. Bennet Omalu discovered this disease in Pittsburgh therefore it was decided that data would be collected from the state of Pennsylvania. The keywords used were "Bennet Omalu," "Dementia," and "Concussion" from September 2015 to April 2016.

\subsubsection{Pancreatic Cancer Datasets}

The initial search was for the keyword "Pancreatic Cancer" from January 2004 - September 2021. After the data was collected and visualized, three major peaks were seen during the months of March 2008, 05 October 2011, 07 March 2019. Upon further research it was discovered that the peak in 2008 was caused because Patrick Swayze who was an American actor, dancer, singer, and songwriter was diagnosed with stage 4 pancreatic cancer. The peak in 2011 was caused due to the death of an American business magnate Steve Jobs. The third peak was in 2019 because Canadian American game host Alex Trebek was diagnosed with cancer. With "Pancreatic Cancer" in mind, it was decided that Google Trends data would be collected on the following key words: "jaundice" and "stomach pain" which are the common symptoms found in pancreatic cancer patients. 
Steve Jobs lived his entire life in the state of California and thus it was decided that data would be collected from his home state. The keywords used were "Steve Jobs," "Jaundice," and "Stomach Pain" from July 2011 to January 2012 in the state of California.

Although Alex Trebek passed away in Los Angeles, he was born in Canada and therefore it was decided that data would be collected from Canada. The keywords used were "Alex Trebek," "Jaundice," and "Stomach Pain" from August 2020 to February 2021 in Canada.

\subsubsection{Lung Cancer Datasets}

The initial search was for the keyword "Lung Cancer" from January 2004 until September 2021. As Lung cancer is seen as a usual form of cancer, the Google Trends search did not immediately yield results with distinct moments of heightened awareness. However, as the data was drilled down, it was noticed that two moments generated more awareness than the rest. March 2006 and February 2021 were the time periods when there was heightened awareness. Upon further research it was discovered that in March 2006, Dana Reeve who was a non-smoker died of lung cancer. The spike in search activity during February of 2021 was caused by the death of the famous American radio personality and political commentator, Rush Limbaugh.

Dana Reeve was an actress who was born in the state of New Jersey and therefore it was decided that data would be collected from her home state. The keywords used were "Dana Reeve," "Fatigue," and "Chest Pain" from January 2006 to June 2006 in the state of New Jersey.

Rush Limbaugh was born in the state of Missouri however he spent his last moments in the state of Florida. Therefore, it was decided that data would be collected using the keywords "Rush Limbaugh," "Fatigue," and "Chest Pain" from November 2020 to April 2021 in the state of Florida.

\section{Results}

An article on Wyzowl titled "The Human Attention Span" has conducted a study stating that in the year 2000, the human attention span was twelve seconds and has shrunk down to only a little over eight seconds (The Human Attention Span [INFOGRAPHIC], 2021). The hypothesis for this research was that there will be an instantaneous increase in searches for a specific celebrity when a significant health event occurs It was also hypothesized that concurrently, there would be an immediate spike in search activity for cause of death. However, after uploading the datasets into Tableau, it was seen that search activity for the health events that were picked were more complicated than initially thought.

Detailed research was done on these diseases which is analyzed below on the three illnesses CTE, Pancreatic disease, Lung Cancer. After the initial analysis was completed on the illnesses, the next step was to analyze the celebrity that was involved along with some key words related to the specific illness.

\section{1 "CTE" Searches using Google Trends}

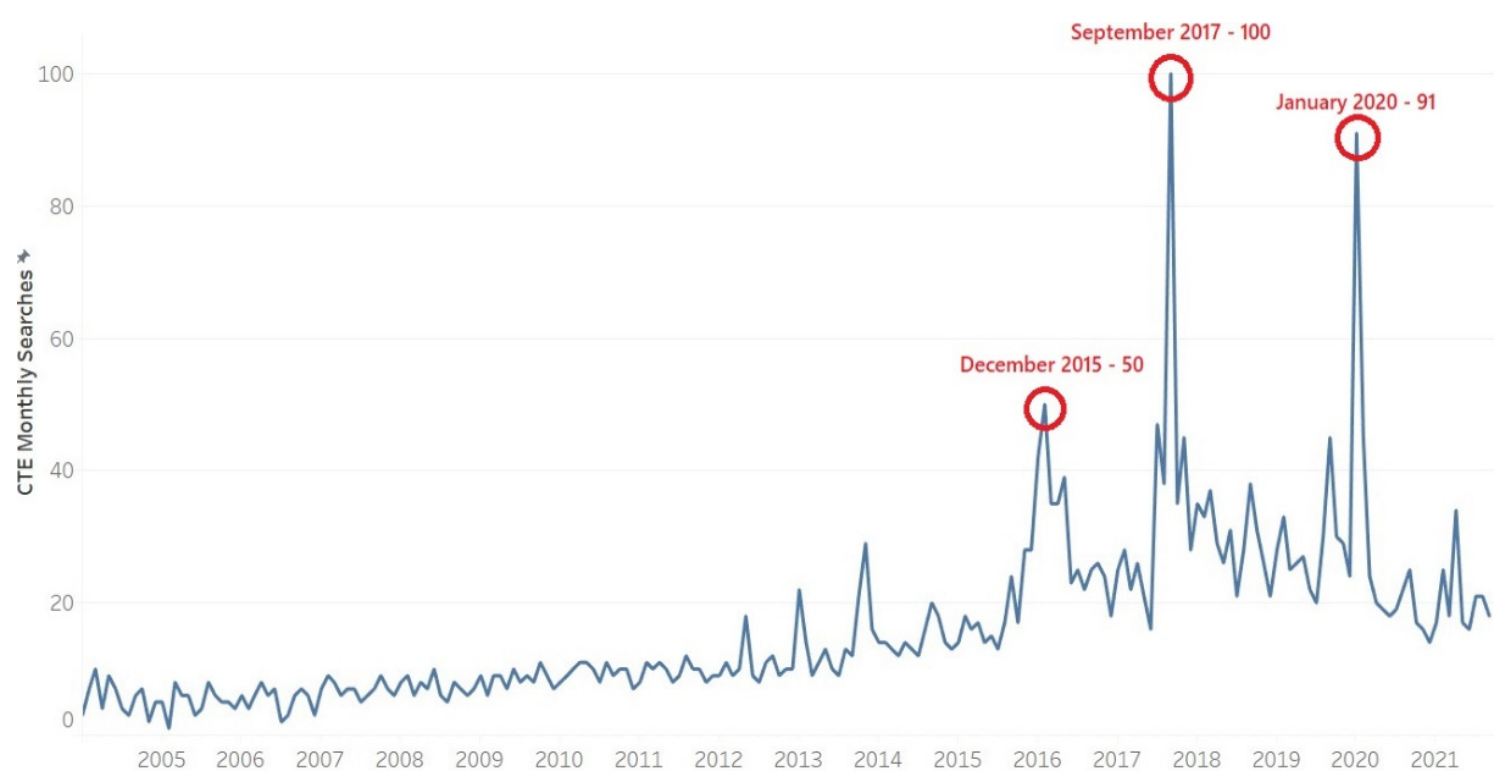

Figure 1. "CTE” searches in the United States using Google Trends from January 2004 - September 2021 
Figure 1 describes the monthly search activity for the keyword "CTE" from January 2004 - September 2021 using data collected using Google Trends. As you can see, three distinct peaks are visible during the months of December 2015, September 2017, and January 2020. December 2015 was the month where the movie "Concussion" was released, and September 2017 was the month where Aaron Hernandez was diagnosed with CTE postmortem.

\section{2 "Aaron Hernandez," "Concussion," \& "Dementia” Searches using Google Trends}

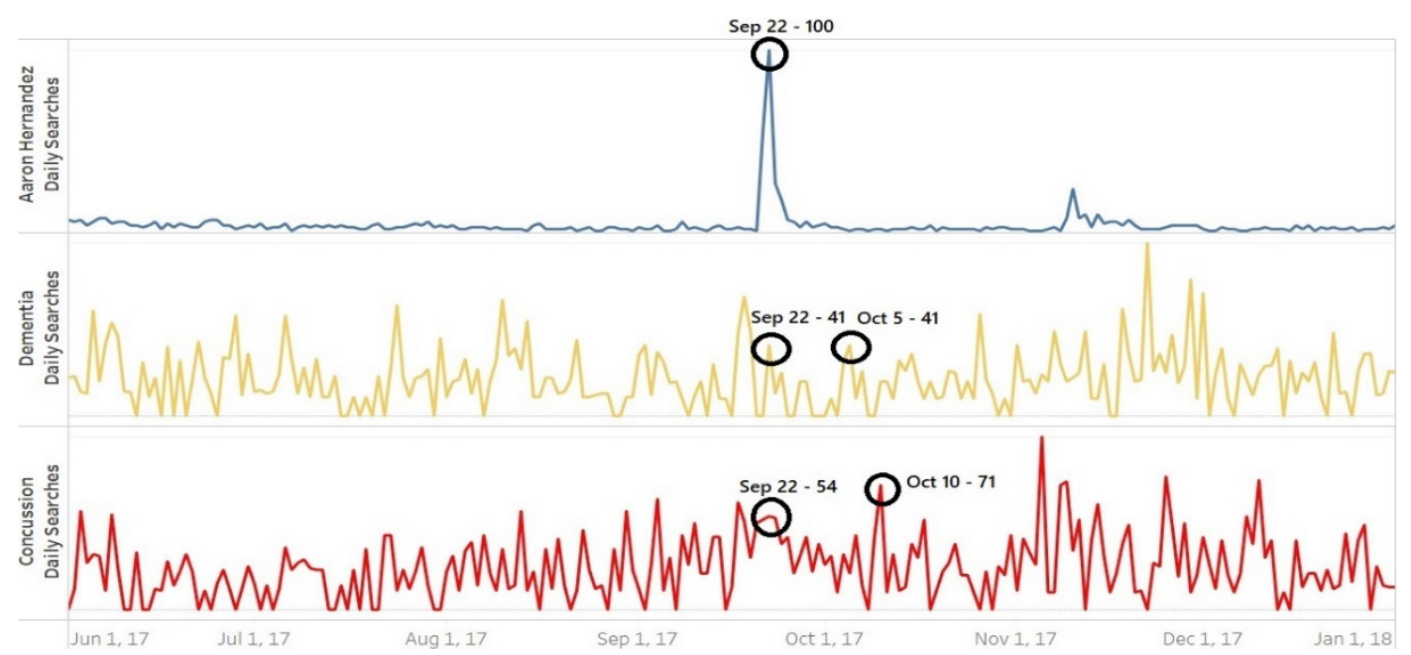

Figure 2. "Aaron Hernandez," "Concussion," \& "Dementia" searches in Massachusetts using Google Trends from June 2017 - January 2018

Figure 2 describes search data for the key words "Aaron Hernandez", "Dementia", and "Concussion" from June 2017 to January 2018 in the state of Massachusetts. "Tests revealed that Aaron Hernandez had 'severe' CTE" on September 22, 2017 (McGovern (2017). Search results for "Aaron Hernandez" were non-existent for most of the time, however searches increased from zero to one hundred on that very day. Searches for "Dementia" increased from zero to forty-one and searches for "Concussion" increased from thirty to fifty-three on September 22, 2017, as well. After the initial spike in searches for all three keywords, the attention seems to die quickly. It takes between fourteen and twenty days for searches for "dementia" and "concussion" to rise once again to either the same levels as September 22, or even greater. On October 5, 2017, searches for "dementia" returned to the level of forty-one which was the same as the day that it was announced that Aaron Hernandez did in fact have CTE. On October 10, 2017, searches for "concussion" rose to seventy-one which exceeded the level on September 22, 2017.

\section{3 "Bennet Omalu," "Concussion," \& "Dementia" Searches using Google Trends}

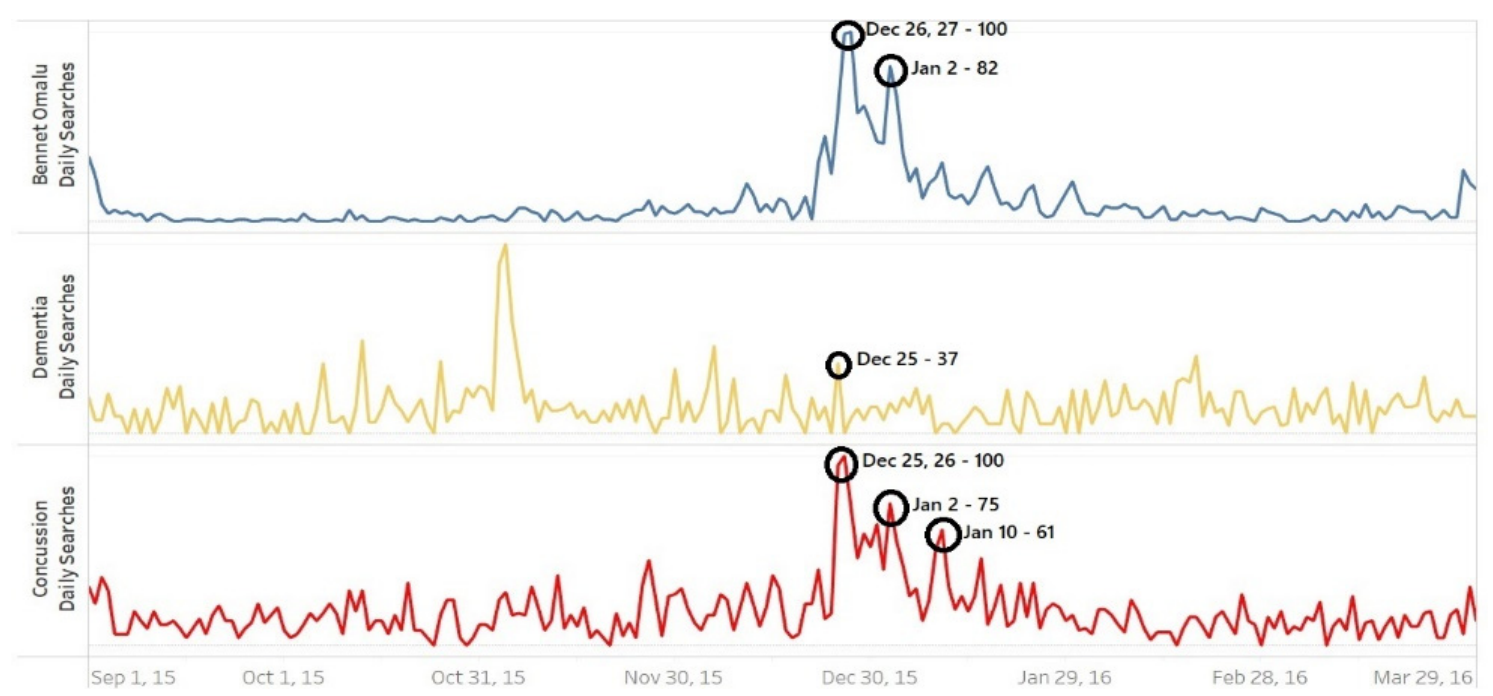

Figure 3. "Bennet Omalu," "Concussion," \& "Dementia" searches in Pennsylvania using Google Trends from September 2015 - April 2016 
Figure 3 describes search data for the keywords "Bennet Omalu", "Dementia", and "Concussion" from September 2015 to March 2016 in the state of Pennsylvania. The Fainaru brothers authored a tell all book titled "League of Denial" which discusses how far the NFL went to hide what they knew regarding disabilities caused by excessive head trauma. One of the main adversaries of the NFL was Dr. Bennet Omalu, the man who discovered CTE by conducting an autopsy on former football Hall of Famer and former Pittsburgh Steeler, Mike Webster. Search results for "Bennet Omalu" started to gradually rise after December 21, 2015. Within four days searches for his name rose from one to one hundred. Searches for "Dementia" increased from zero to thirty-seven and searches for "Concussion" increased from four to one hundred from December 18 to December 25, 2015. Because of the star power of the lead actor for the movie Will Smith, the keywords "Bennet Omalu" and "Concussion" remained hot topics until around January 7, 2016, even though searches did not completely die down until around the first week of February 2016. Searches for "dementia" however never returned close to the thirty-seven it reached on December 25, 2015.

\section{4 "Pancreatic Cancer" Searches using Google Trends}

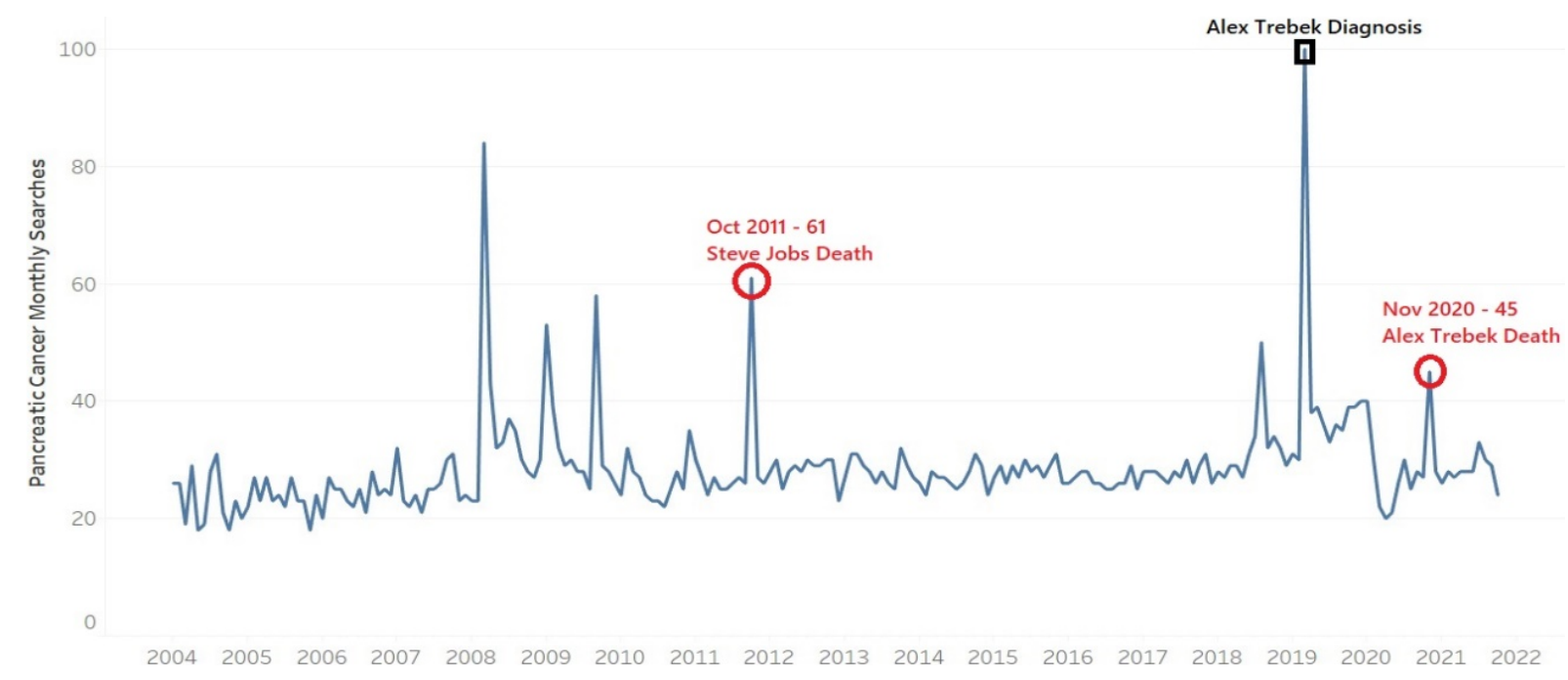

Figure 4. "Pancreatic Cancer" searches in the United States using Google Trends from January 2004-September 2021

Using Google Trends data from January 2004 to September 2021 five distinct peaks were noticed. The first major peak was caused by the death of an American actor, Patrick Swayze. However, his death did not influence the other keywords and that is why this date was omitted in the analysis. The peak in October 2011 was followed by a long hiatus of searches for Pancreatic Cancer until March 2019. It was discovered that the peak in October 2011 was caused by the death of Steve Jobs who was the founder of Apple. The peak in March 2019 was caused by the announcement of Alex Trebek's diagnosis of Pancreatic Cancer. He was the beloved host of Jeopardy! For thirtyseven seasons from its revival in 1984 until his death in 2020. It was decided that instead of an analysis on the date of the announcement of his illness, it would be best to analyze his death date. Further analysis was done on those dates for the keywords "Alex Trebek," "Steve Jobs," "Jaundice," and "Stomach Pain." 
3.5 “Alex Trebek," “Jaundice,” \& “Stomach Pain” Searches by Google Trends

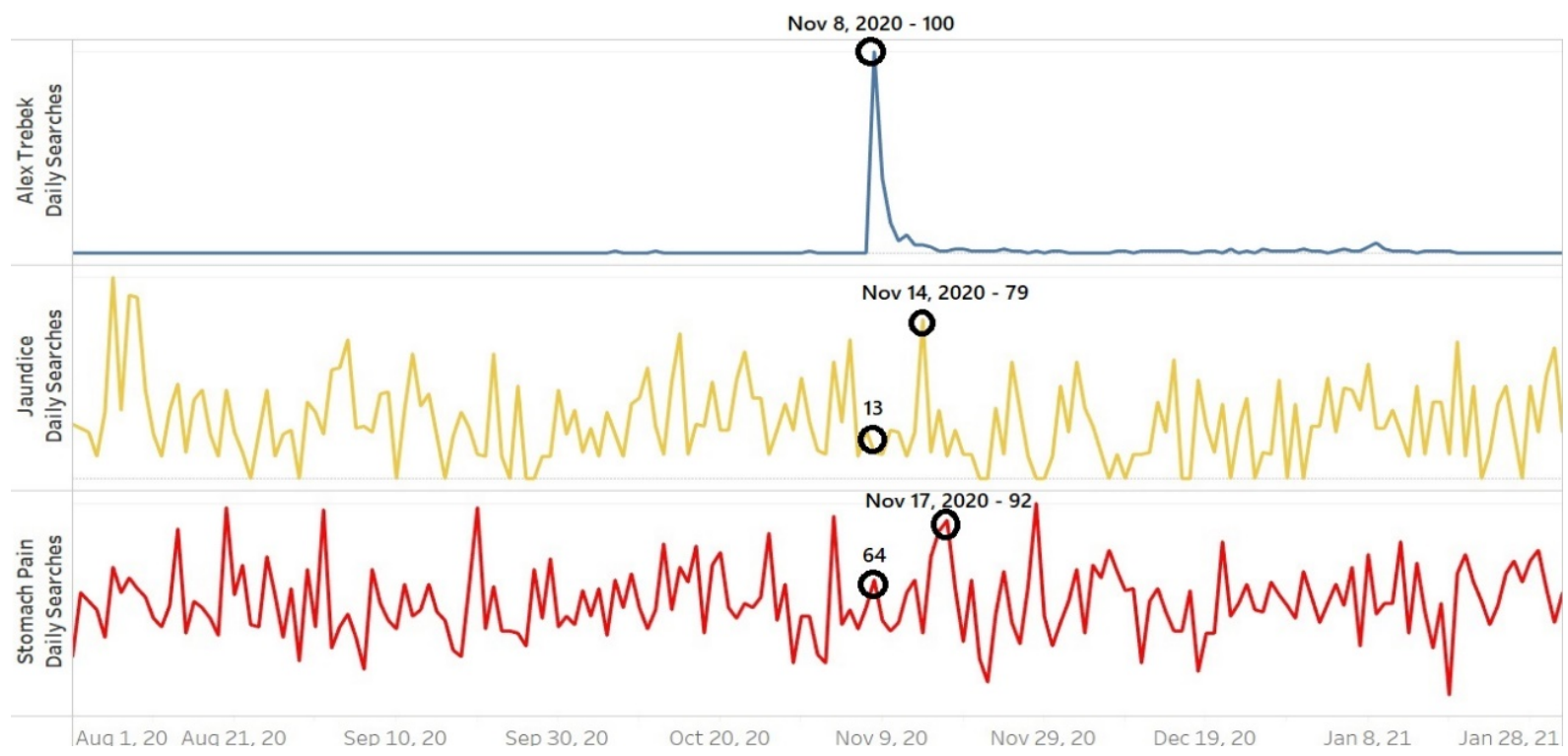

Figure 5. "Alex Trebek," "Jaundice," \& "Stomach Pain" searches in Canada using Google Trends from August 2020 - February 2021

Figure 5 shows the results of the keyword searches "Alex Trebek", "Jaundice", and "stomach pain" from August 2020 to February 2021. Search results for "Alex Trebek" rose to one hundred on Nov 8, 2020, because of his death in Los Angeles, CA due to pancreatic cancer. Searches for "Jaundice" increased around seventy-nine in the same month because Jaundice is found in appx $70 \%$ of pancreatic cancer patients. At the same time, search results for "Stomach Pain" increase to ninety-two as it is also among common symptoms found in patients. All correlated with events in the media. As already mentioned, he was a Canadian American game show host and television personality hence was more popular in Canada as a result search were more on the geographical part.

3.6 "Steve Jobs," "Jaundice," \& "Stomach Pain” Searches using Google Trends

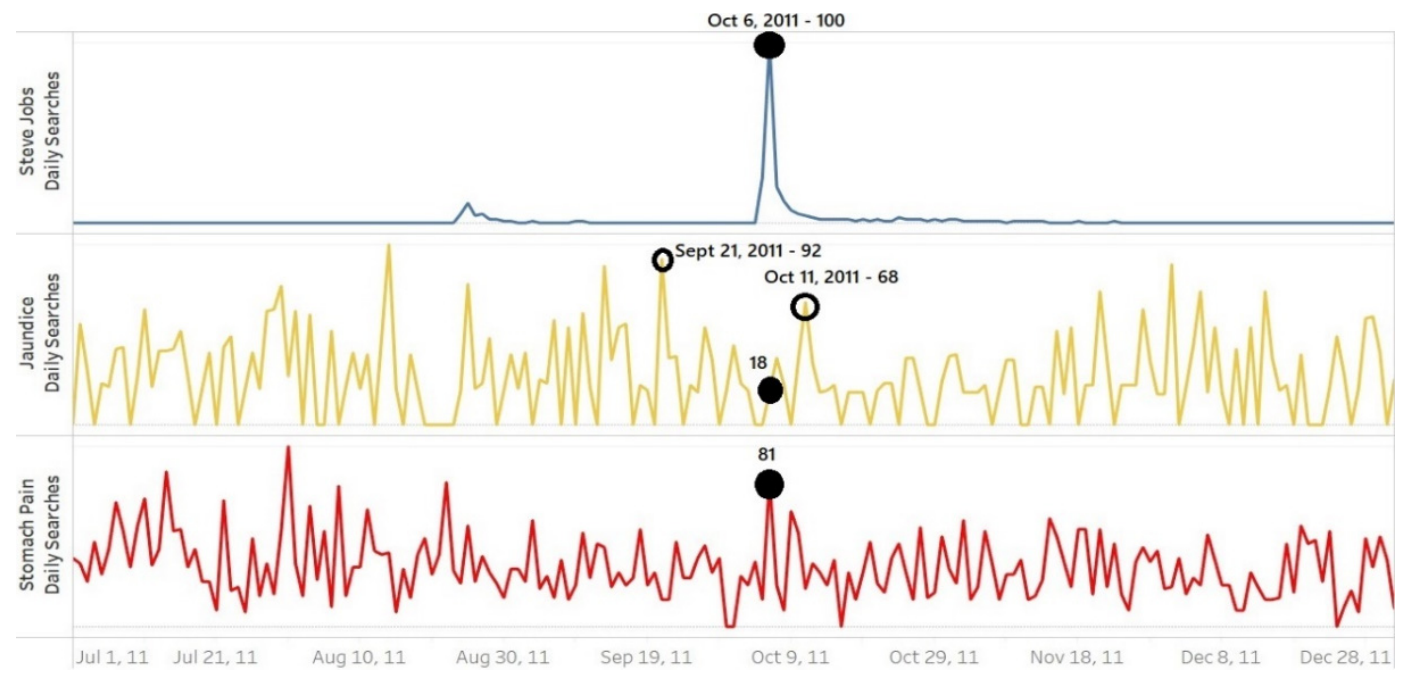

Figure 6. "Steve Jobs," "Jaundice," \& "Stomach Pain" searches in California using Google Trends from July 2011 - January 2012

Figure 6 shows the results of the keyword searches "Steve Jobs", "Jaundice", and "Stomach Pain" from July 2011 to January 2012. Search results for "Steve Jobs" peaked on 6 Oct 2011 because he died on October 5, 2011. Next day it was breaking news and media coverage was at top hence people were more queries to know about him and because of his death. Search result was one hundred for Steve jobs, simultaneously people also searched keywords 
like jaundice and Stomach pain which are the symptoms of pancreatic cancer. Five days after his death, searches for "Jaundice" rose to sixty-eight, however on the day of his death searches were minimal at eighteen. Searches for "Jaundice" were much higher two weeks prior to his death. On September 21, 2011, search results for "Jaundice" were recorded at ninety-two. Because Steve Jobs lived his entire life in the state of California, the data was retrieved from his home state.

\section{7 "Lung Cancer" Searches using Google Trends}

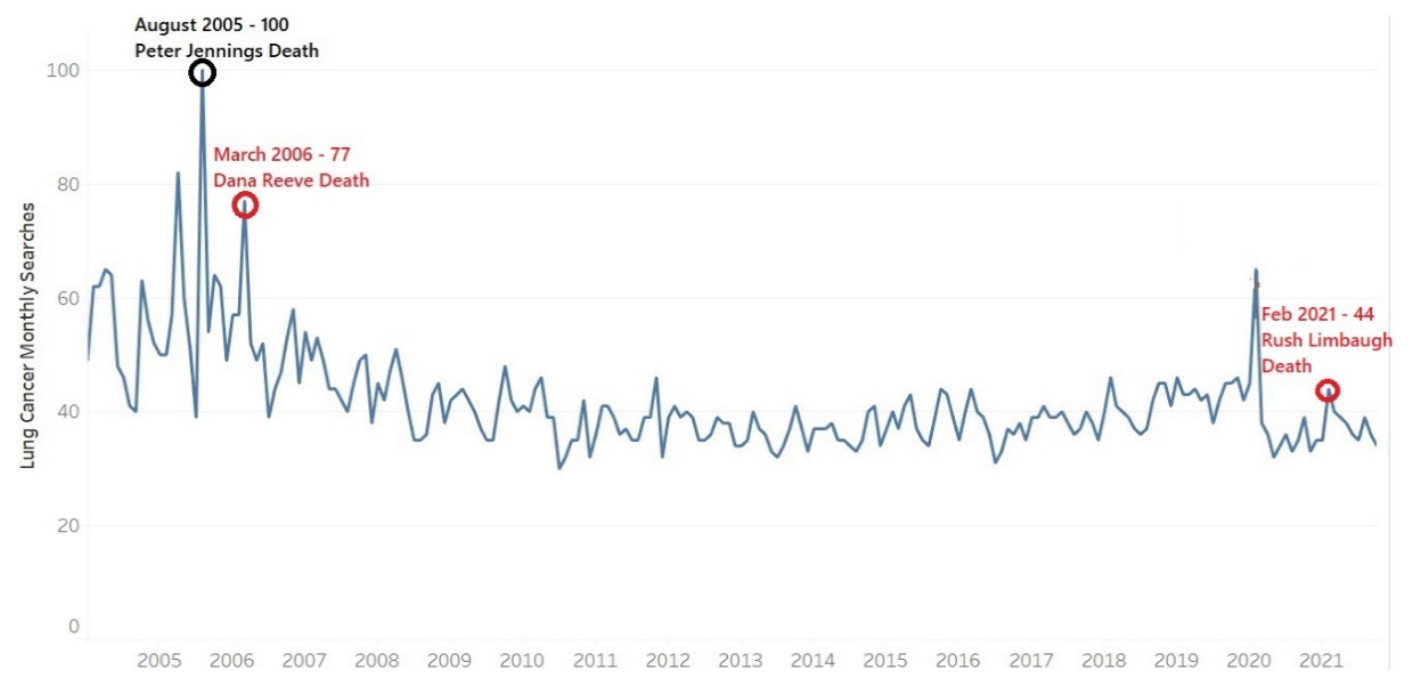

Figure 7. "Lung Cancer" searches in the United States using Google Trends from January 2004 - September 2021

Using Google Trends data from January 2004 to September 2021 four distinct peaks were noticed. The first two peaks were considered for this research however upon further investigation, the deaths that occurred on those days did not influence the other key words that were going to be analyzed for this portion of the research. As shown in Figure 7 the first spike in searches that was looked at was in March 2006 which was caused by the death of Dana Reeve who was a non-smoker. The second spike that was looked at was in February 2021 which was caused by the death of Rush Limbaugh who was a chain smoker.

\section{8 "Dana Reeve," "Fatigue," \& “Chest Pain" Searches using Google Trends}

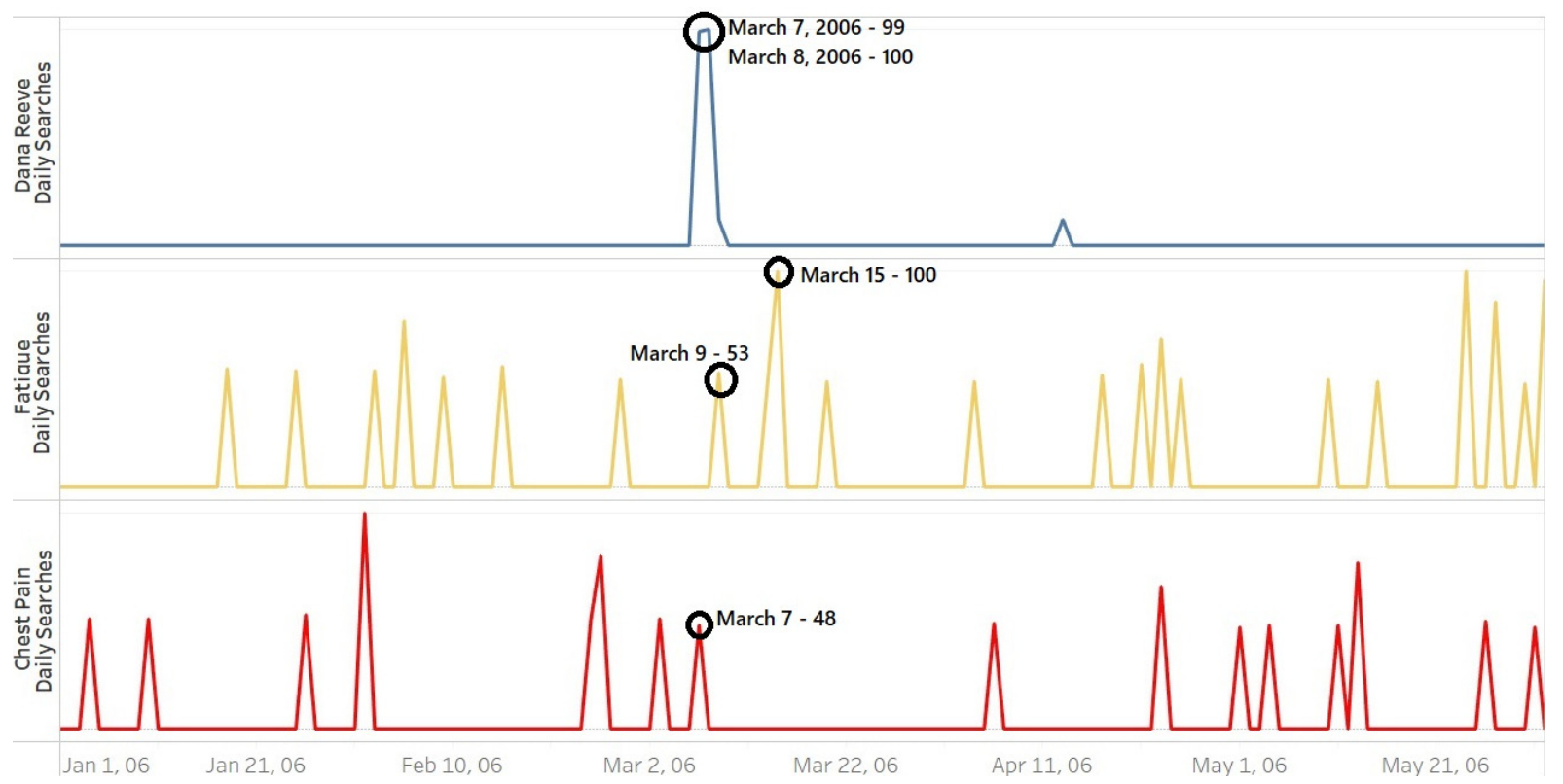

Figure 8. "Dana Reeve," "Fatigue," \& "Chest Pain" searches in New Jersey using Google Trends from January 2006 - June 2006 
Figure 8 shows that searches for "Dana Reeve" leading up to her death were virtually zero. However, the searches spiked to ninety-nine on March 7 which is the day that she died, and they rose to one hundred the following day. The two key words that research was conducted on were "Fatigue" and "Chest Pain." This is because these were the only symptoms that triggered some response to her death. Two days after her death, "Fatigue" spiked to fiftythree and after declining for a week the search rose back to one hundred. Searches for "Chest Pain" only rose on March 7 to forty-eight. Because Dana Reeve was born in New Jersey, the data was collected from her home state.

\section{9 "Rush Limbaugh," "Fatigue," \& "Chest Pain" Searches using Google Trends}

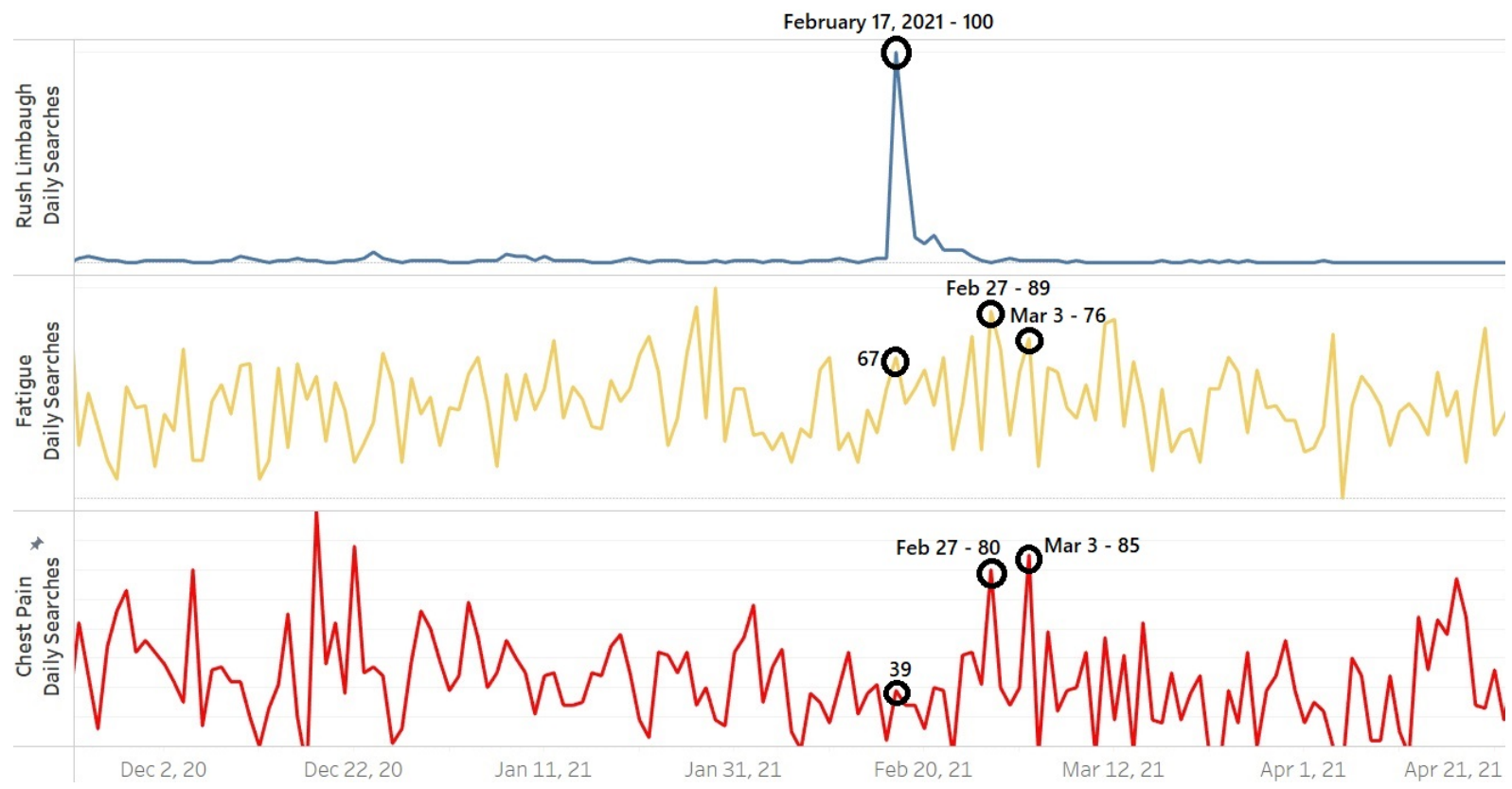

Figure 9. "Rush Limbaugh," "Fatigue," \& "Chest Pain" searches in Florida using Google Trends from

November 2020 - May 2021

Figure 9 shows a similar picture just as in all the previous situations, searches for "Rush Limbaugh" were nonexistent until the day that he died where searches reached one hundred. The same day searches for "Fatigue" reached sixty-seven and searches for "Chest Pain" reached only thirty-nine. However, this changed after ten days where searches on February 27 for "Fatigue" reached eighty-nine and searches for "Chest Pain" reached eighty. On March 3, searches for "Fatigue" reached seventy-six and searches for "Chest Pain" reached eighty-five. Although Rush Limbaugh was not from Florida, he did pass away in that state. For that reason, search data was collected from the state of Florida.

\subsection{Overview of Deaths}

This research decided to look at the annual total deaths for each disease to understand if these prominent health moments have had any influence thus far. However, in most cases it is seen that deaths are rising for each disease annually. The data for CTE is inconclusive because it is unknown how many current players are suffering from this disease and what impact it will have on their life.

An analysis on the total annual deaths for each disease is presented in this section. For the illnesses pancreatic cancer and lung cancer, total annual deaths data is between years of 1990 and 2016. For the illness CTE, total annual deaths data is between years of 2002 and 2019. 


\subsubsection{CTE Deaths}

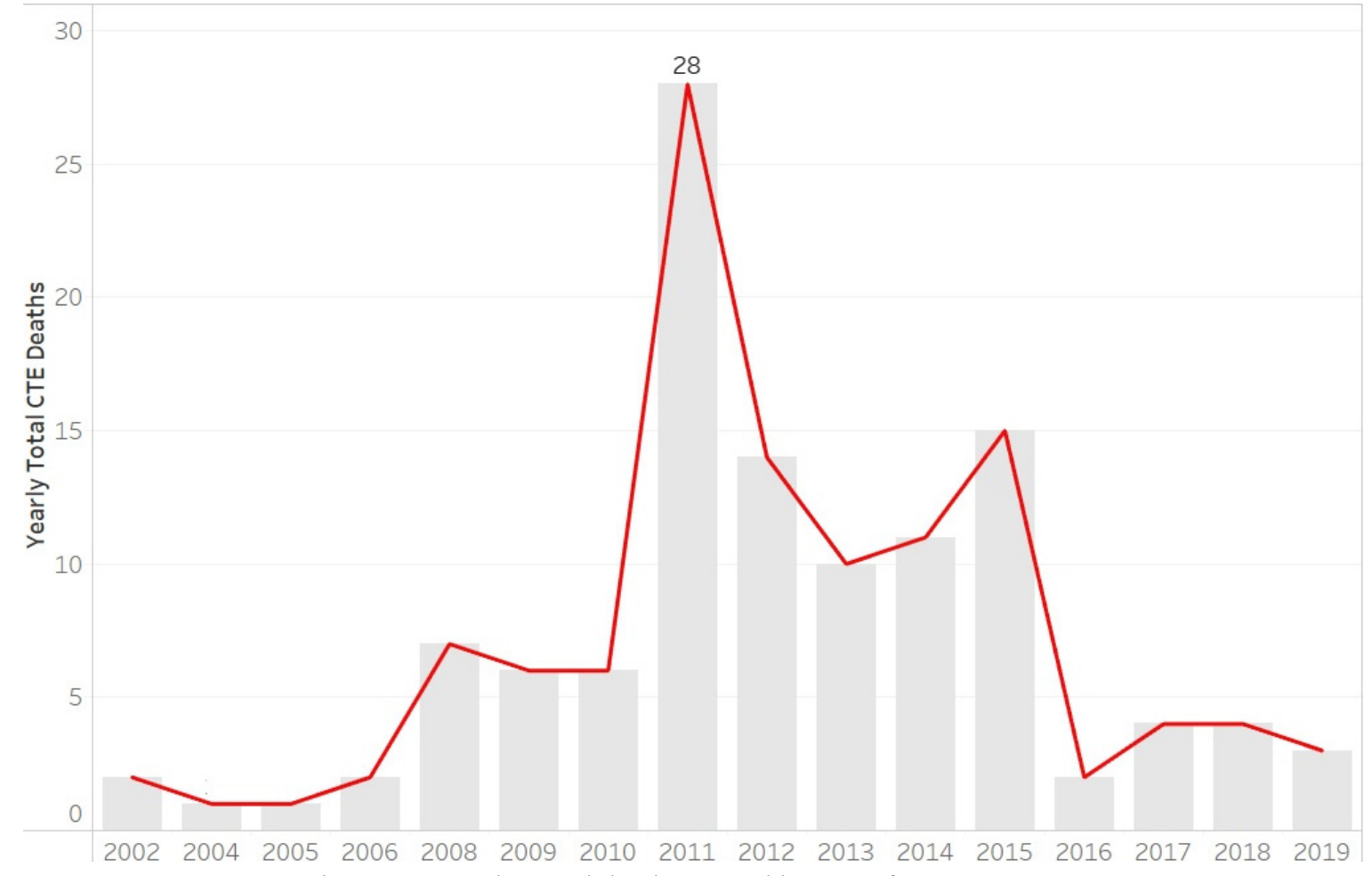

Figure 10. Total annual deaths caused by CTE from 2002-2019

Figure 10 shows the total number of former NFL players whose brains had CTE after their death. Since CTE is an illness that can only be diagnosed postmortem, there is no definitive number for how many current NFL players are suffering from this illness. Furthermore, because CTE was only discovered in 2002 it is unknown how many players in the past have also had this illness.

Boston University is the preferred Brain Bank of the NFL and based on their research they have found "CTE in $99 \%$ of former NFL players studied". As more players decide to donate their brains, a better understanding can be seen as to how much bigger of an issue CTE is.

\subsubsection{Pancreatic Cancer Deaths}

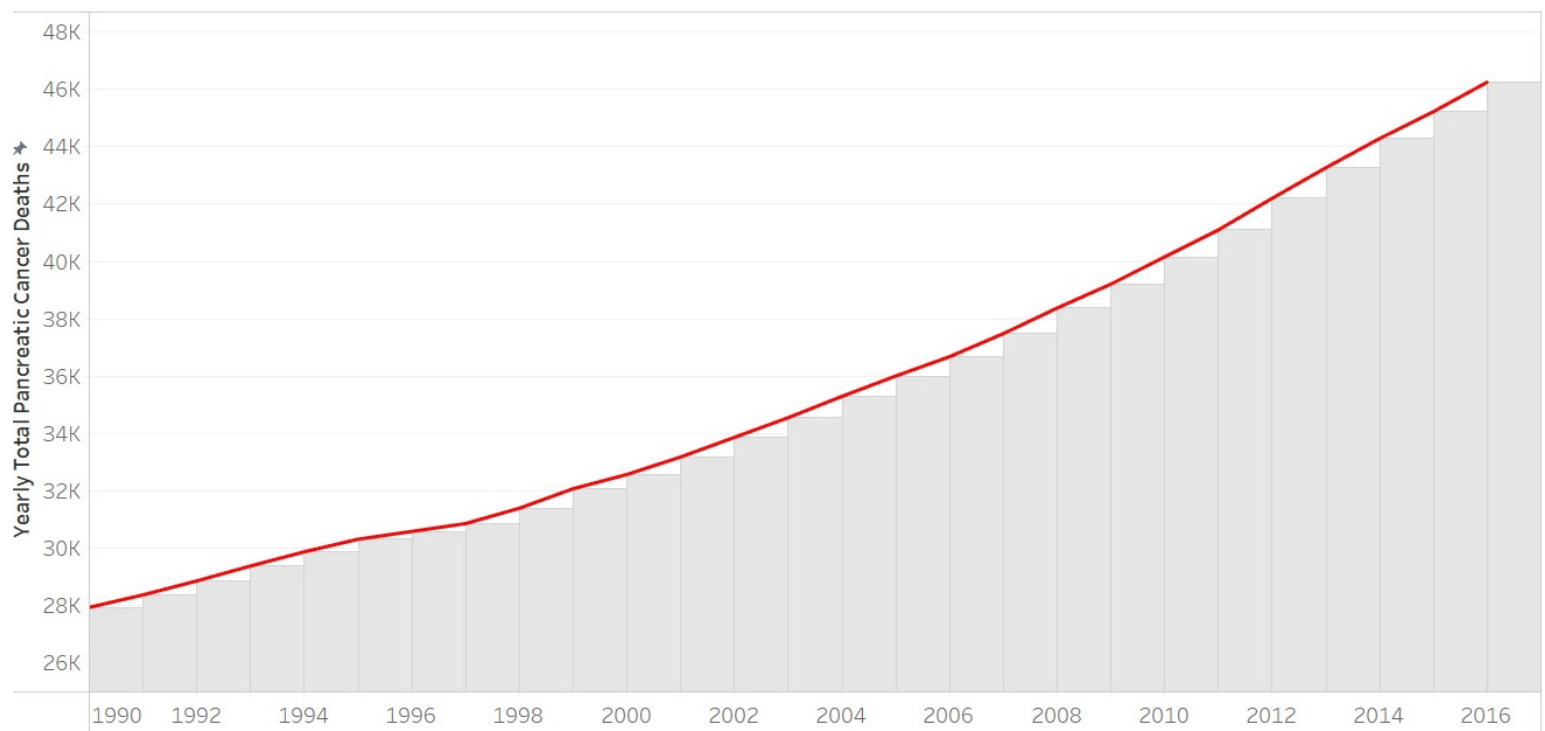

Figure 11. Total annual deaths caused by Pancreatic Cancer from 1990-2016 
Figure 11 addresses the total annual deaths for pancreatic cancer from 1990 - 2016. It is found that there is a continuous year on year increase in the number of deaths. Pancreatic cancer has the highest mortality rate of all major cancers. For all stages combined, the 5 -year relative survival rate is $10 \%$. Even for the small percentage of people diagnosed with local disease, the 5-year survival is only $39 \%$. There are no detection tools to diagnose the disease in its initial stages. The causes of pancreatic cancer are not fully understood. However, certain personal, environmental, health, and inherited risk factors have been identified that increase the chances of a person developing the disease.

\subsubsection{Lung Cancer Deaths}

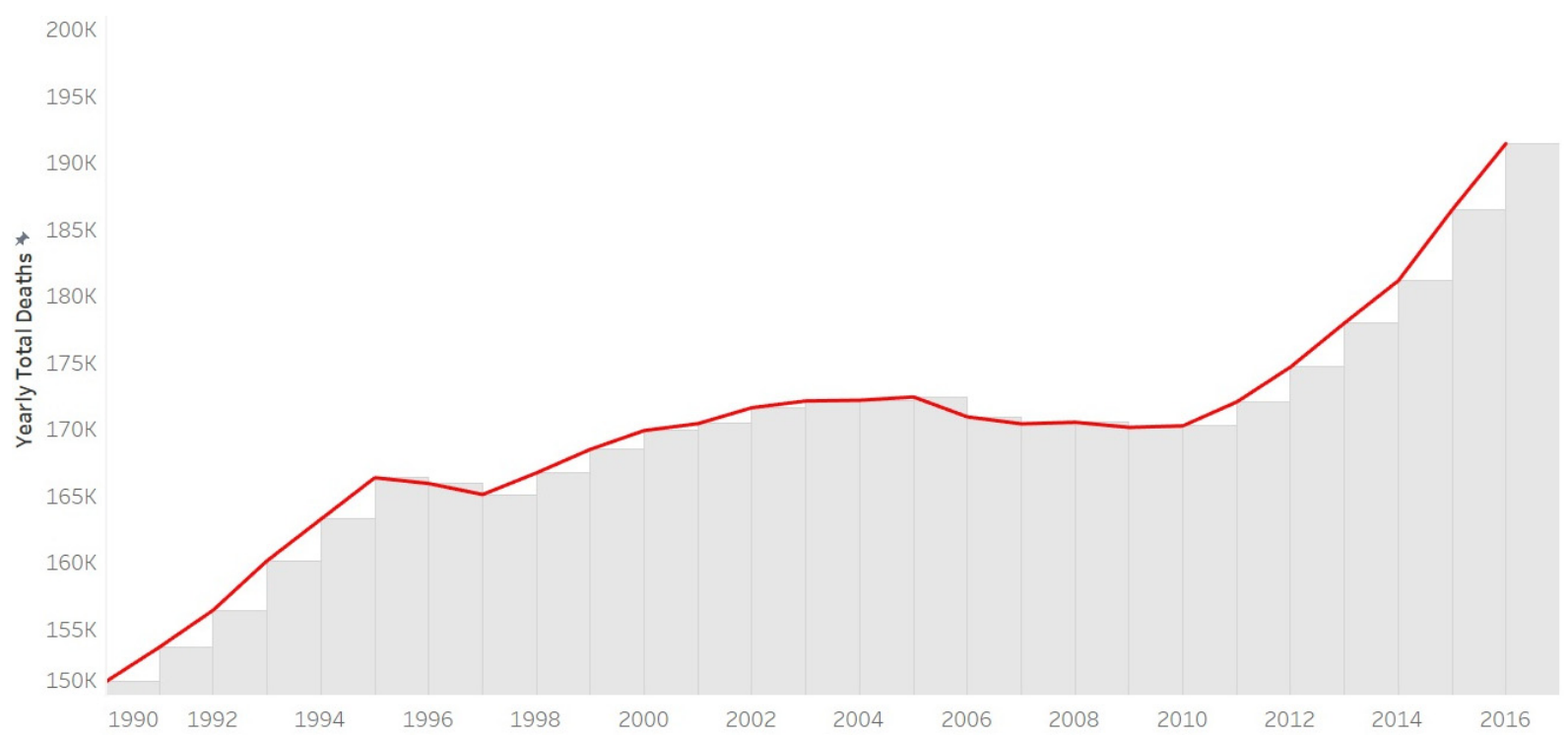

Figure 12. Total annual deaths caused by Lung Cancer from 1990-2016

Figure 12 visualizes the total annual deaths for lung cancer from the years 1990-2016. The deaths were one hundred fifty thousand in the year 1990 where today they have risen to two hundred thousand. Lung cancer is by far the leading cause of cancer death among both men and women, making up almost $25 \%$ of all cancer deaths.

Statistics on survival in people with lung cancer vary depending on the stage of the cancer when it is diagnosed. The main cause for lung cancer is Smoking, which is sadly neglected by people which results in their death. Even though anti-smoking campaigns already exist, lung cancer deaths have continued to rise.

\section{Discussion}

When observing the data on CTE for the case of Aaron Hernandez, searches for his name increased from one to one hundred, "Dementia" increased from zero to forty-one and searches for "Concussion" increased from thirty to fifty-three. After the initial searches began to die down, it took between fourteen and twenty days for searches for "dementia" and "concussion" to rise once again to either the same levels or even greater. Searches for "dementia" returned to forty-one on October 5 and searches for "concussion" rose to seventy-one on October 10.

In the case of Dr. Bennet Omalu, searches for his name remained high for a longer period due to the star power of the movie "Concussion." Search results for "Bennet Omalu" began to rise after December 21,2015 and stayed high throughout the first week of January. Searches for "Concussion" followed a similar trend due to it being the name of the movie. Those searches also stayed high until the first week of January. Both keywords did not see a complete fall off until the first week of February. Searches for "dementia" rose quickly during the week of the movie's release however those searches quickly fell and never returned.

On the day of Alex Trebek's death, searches for "Jaundice" only rose to thirteen and searches for "Stomach Pain" rose to sixty-four. Searches for "Jaundice" rose to seventy-nine six days later while searches for "Stomach Pain" rose to ninety-two nine days later. When Steve Jobs passed, "Jaundice" only rose to eighteen while "Stomach Pain" rose to eighty-one. Interestingly, searches for "Jaundice" were higher two weeks prior to his death at ninety-two whereas searches for "Stomach Pain" did not see any changes.

For Dana Reeve, searches for "Chest Pain" only increased on the day of her death however searches for "Fatigue" rose two days after her death to fifty-three and then again eight days after her death to one hundred. On the day of 
Rush Limbaugh's death, searches for "Fatigue" rose to sixty-seven while "Chest Pain" only rose to thirty-nine. However, after about ten days, searches for "Fatigue" rose to eighty-nine and seventy-six while searches for "Chest Pain" rose to eighty and eighty-five.

Based on this research it seems that when a celebrity passes away, there is an instantaneous rise in searches for the specific celebrity. Depending on how important this figure was, the searches may last anywhere from 1 to 3 days. In addition to these initial searches for the celebrity's name, it takes around nine days for searches to shift from the celebrity to one of the symptoms. In the case of Dr. Bennet Omalu, this research was showing better results due to the star power of the movie "Concussion." If the marketing done for a movie can already create a heightened sense of awareness, this time would be ideal for an organization to use to spread more awareness.

One aspect of this research which created obstacles was the data collection process. The only source of search data for this research was from Google Trends. This research could be enriched if data can be collected from social media platforms such as Facebook and Twitter in accordance with Google Trends Data. Twitter would be a notable example because instead of searching for keywords, people would be writing their opinions on a specific subject. Using this, better insights could be drawn on public perception. The secondary data consist of total annual deaths for the illnesses. This was also an obstacle because the data is not current for many of the diseases. For CTE specifically, there is not a vast amount of public data available due to the negative connotation it would provide to the game of football. With more current data, better insights could be drawn to see if marketing campaigns are influencing total annual deaths.

In this research various datasets were used to do analysis which is related to famous personalities, diseases they were suffering from and overall death due to disease. It made the research more comprehensive and meaningful. For future recommendation, this research will inspire the extension study of searching awareness on more critical diseases with advanced tools and its effect on other industries such as insurance, finance and so on.

\section{Acknowledgments}

We would like to thank Dr. Joseph W. Gilkey Jr. from Guarini School of Business at Saint Peter's University for his contribution in this research paper.

\section{Funding Source}

This research did not receive any outside funding or support.

\section{Conflict of interests}

The authors declare that there is no conflict of interest.

\section{References}

Dolak, D. C. A. K. (n.d.). Steve Jobs' Pancreatic Cancer: A Timeline. ABC News. Retrieved December 1, 2021, from https://abcnews.go.com/Health/CancerPreventionAndTreatment/steve-jobs-pancreatic-cancertimeline/story?id=14681812

Lindsley, C. W. (2017). Chronic Traumatic Encephalopathy (CTE): A Brief Historical Overview and Recent Focus

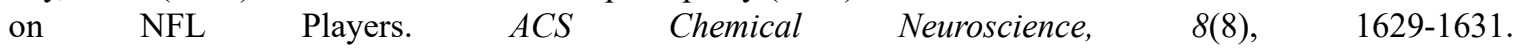
https://doi.org/10.1021/acschemneuro.7b00291

DATA POINTS: CANCER DEATHS. (2006). Scientific American, 294(4), 32. https://doi.org/10.1038/scientificamerican0406-32a

Geda, M., George, S. Z., Burgess, D. J., Scarton, D. V., ... Peduzzi, P. (2020). Strategy for addressing researchsite overlap in pragmatic clinical trials: lessons learned from the NIH-DOD-VA Pain Management Collaboratory (PMC). Trials, 21(1). https://doi.org/10.1186/s13063-020-04941-8

Alosco, M. L., Cherry, J. D., Huber, B. R., ... McKee, A. C. (2020, October). Characterizing tau deposition in Chronic traumatic encephalopathy (CTE): Utility of the mckee CTE staging scheme. Acta neuropathological. Retrieved November 5, 2021, from https://www.ncbi.nlm.nih.gov/pmc/articles/PMC7914059/

Alosco, M. L., Mariani, M. L., Adler, C. H., Balcer, L. J., Bernick, C., Au, R., Banks, S. J., Barr, W. B., Bouix, S., Cantu, R. C., Coleman, M. J., Dodick, D. W., Farrer, L. A., Geda, Y. E., Katz, D. I., Koerte, I. K., Kowall, N. W., Lin, A. P., Marcus, D. S., ... DIAGNOSE CTE Research Project Investigators. (2021, August 12). Developing methods to detect and diagnose chronic traumatic encephalopathy during life: Rationale, design, and methodology for the diagnose CTE research project. Alzheimer's research \& therapy. Retrieved November 5, 2021, from https://www.ncbi.nlm.nih.gov/pmc/articles/PMC8357968/

Blandin Knight, S., Crosbie, P. A., Balata, H., Chudziak, J., Hsell, T., \& Dive, C. (2017, September). Progress and 
prospects of early detection in lung cancer. Open biology. Retrieved November 5, 2021, from https://www.ncbi.nlm.nih.gov/pmc/articles/PMC5627048/.

Fainaru-Wada, M., \& Fainaru, S. (2014). League of denial: The NFL, concussions, and the Battle for Truth. Three Rivers Press.

Kaleem, T., Malouff, T. D., Stross, W. C., Waddle, M. R., Miller, D. H., Seymour, A. L., Zaorsky, N. G., Miller, R. C., Trifiletti, D. M., \& Vallow, L. (2019, August 10). Google search trends in oncology and the impact of Celebrity cancer awareness. Cureus. Retrieved November 5, 2021, from https://www.ncbi.nlm.nih.gov/pmc/articles/PMC6783227/

Kilgore, A. (2017, November 9). Aaron Hernandez suffered from most severe CTE ever found in a person his age. The Washington Post. Retrieved November 5, 2021, from https://www.washingtonpost.com/sports/aaronhernandez-suffered-from-most-severe-cte-ever-found-in-a-person-his-age/2017/11/09/fa7cd204-c57b-11e7afe9-4f60b5a6c4a0_story.html

McGovern, B. (2018, November 17). Tests reveal Aaron Hernandez had 'severe' CTE. Boston Herald. Retrieved November 5, 2021, from https://www.bostonherald.com/2017/09/22/tests-reveal-aaron-hernandez-hadsevere-cte/

McGuigan, A., Kelly, P., Turkington, R. C., Jones, C., Coleman, H. G., \& McCain, R. S. (2018, November 21). Pancreatic cancer: A review of clinical diagnosis, epidemiology, treatment, and outcomes. World journal of gastroenterology. $\quad$ Retrieved November $\quad 5, \quad 2021, \quad$ from https://www.ncbi.nlm.nih.gov/pmc/articles/PMC6250924/

NBCUniversal News Group. (2021, February 20). Rush Limbaugh died from lung cancer after denying smoking's risk. why'd he believe his lie? NBCNews.com. Retrieved November 5, 2021, from https://www.nbcnews.com/think/opinion/rush-limbaugh-died-lung-cancer-after-denying-smoking-s-riskncna1258395

Ruth, D., Freed, A., F., J., Moulding, D., Jumbalaya, J., Hall, J., Debeau, M., Bj, Parker, Z., Treu, J., Bright, T., Mist, Brandon, Mike, Demestihas, J., Greatfon.com, \& Schwartzkopff, D. L. (2017, July 26). BU researchers find CTE in $99 \%$ of former NFL players studied. Boston University. Retrieved November 5, 2021, from https://www.bu.edu/articles/2017/cte-former-nfl-players/

Seifert, K. (2017, August 4). Dr. Bennet Omalu: CTE obsession obscuring truth about brain health of football players. ESPN. Retrieved November 5, 2021, from https://www.espn.com/nfl/story/_/id/20245394/dr-bennetomalu-says-obsession-cte-obscuring-larger-truth-brain-health-football-players

The human attention span [infographic]. Wyzowl. (n.d.). Retrieved November 5, 2021, from https://www.wyzowl.com/human-attention-span/

The priority of Cancer Research - project by Jasonwithjulia. data.world. (2018, October 7). Retrieved November 5, 2021, from https://data.world/jasonwithjulia/the-priority-of-cancerresearch/workspace/file?filename=total-cancer-deaths-by-type.csv

Ugwu, R., \& Levenson, M. (2020, August 29). 'black panther' star Chadwick Boseman dies of cancer at 43. The New York Times. Retrieved November 5, 2021, from https://www.nytimes.com/2020/08/28/movies/chadwick-boseman-dead.html

What causes pancreatic cancer? What Causes Pancreatic Cancer?: The Pancreas Center| Columbia University Department of Surgery. (n.d.). Retrieved November 5, 2021, from https://columbiasurgery.org/pancreas/whatcauses-pancreatic-cancer

\section{Copyrights}

Copyright for this article is retained by the author(s), with first publication rights granted to the journal.

This is an open-access article distributed under the terms and conditions of the Creative Commons Attribution license (http://creativecommons.org/licenses/by/4.0/). 